\title{
Infection of total hip prostheses by Peptococcus magnus: an immunofluorescence and ELISA study of two cases
}

\author{
A. G. TAYLOR ${ }^{1}$, W. J. FINCHAM, M. A. GOLDING, AND JOSEPHINE COOK \\ From the Department of Clinical Pathology, The Institute of Orthopaedics (University of London), Royal \\ National Orthopaedic Hospital, Stanmore, Middlesex HA7 4LP, UK
}

SUMmary In two cases of infected total hip replacements, Peptococcus magnus was isolated in pure culture from the implant when it was removed. Fluorescent antibody and ELISA studies have shown that both patients developed an antibody response to this anaerobic coccus soon after the replacement operation. These results suggest that the organism is a true infective agent, which was probably responsible for the failure of the arthroplasty operation.

The anaerobic Gram-positive cocci, in addition to being common constituents of the normal human microflora, have frequently been implicated as causative agents in a wide range of infections (Lambe et al., 1974). The genus peptococcus has been isolated more frequently than the peptostreptococcus, the most common species being Peptococcus prevotii, Peptococcus asaccharolyticus, Peptococcus variabilis, and Peptococcus magnus.

Recent reports have described the isolation of anaerobic cocci from cases of infection in total hip replacements. Evanski et al. (1977), in a study of 387 operations, reported nine infections, three of which were due to Peptococcus sp and, in a study of 16 cases of deep sepsis after total hip replacement, Nelson (1977) described the isolation of peptococci in three instances.

In this paper two cases of infections after total hip replacement are described. Removal of the prostheses was eventually considered to be necessary, and $\boldsymbol{P}$. magnus was then isolated in pure culture from the implants in both cases. We present serological evidence indicating that the infections by this organism became established long before the prostheses were removed. This study emphasises the need for careful bacteriological study of prostheses removed from cases where infection is suspected and demonstrates the usefulness of serum samples taken preoperatively

'Present address: Standards Laboratory for Serological Reagents, Central Public Health Laboratory, Colindale Avenue, London NW9 5HT, UK.

Received for publication 20 June 1978 and postoperatively for retrospective serological studies.

\section{Material and methods \\ BACTERIOLOGICAL EXAMINATION OF PROSTHESES}

Examination of prostheses in our laboratory has been designed to ensure isolation of both aerobic and anaerobic bacteria and also to allow estimation of the numbers of any organisms present in the material. This quantitation of the bacterial population was made so that small numbers of airborne or skinderived organisms, which might contaminate the prosthesis during its removal, would not be given undue significance.

Immediately after the surgeon had removed the prosthesis it was placed in a sterile container in the operating theatre for immediate transfer to the bacteriology department. In the laboratory $20 \mathrm{ml}$ of digest broth was added to the container, which was then manipulated by hand so that the whole surface of the prosthesis was washed. Two pour-plates were made by adding $1 \mathrm{ml}$ of this broth to $15 \mathrm{ml}$ of molten digest agar at $50^{\circ} \mathrm{C}$ for each plate. A loopful of broth was inoculated onto two blood plates, and the remaining broth was incubated aerobically at $37^{\circ} \mathrm{C}$ and subcultures were made after 24 and 72 hours. One pour-plate and one blood plate were incubated aerobically, and the other pair of plates anaerobically, for not less than 48 hours. A count of the number of colonies present in the pour-plates after incubation was made, and the number of bacteria 
washed from the prosthesis was calculated. The organisms were then identified by standard methods.

The antibiotic sensitivities of organisms isolated were determined by the disc method (Mastring-S discs, Mast Laboratories Ltd, Liverpool).

\section{INDIRECT FLUORESCENT ANTIBODY METHOD}

\section{Preparation of antigen slides}

After identification the strains of $P$. magnus isolated were cultured for 48 hours in digest broth at $37^{\circ} \mathrm{C}$ under anaerobic conditions. The growth was harvested by centrifugation and washed once with phosphate buffered saline, $\mathrm{pH} 7.6$ (PBS), and then twice with distilled water, which was also used for making the final antigen suspension.

\section{Titration of sera}

The microscope slides were prepared as described by Kidby (1974). The concentration of organisms found to be optimal for making the slides gave an $\mathrm{E}_{605 \mathrm{~nm}}^{1 \mathrm{~cm}}$ of $0 \cdot 3$. Approximately $50 \mu \mathrm{l}$ of the bacterial suspension was placed in each $5 \mathrm{~mm}$ diameter sample area and dried with a current of warm air.

Dilutions of the patients' sera ranging from 1/10 to $1 / 2560$ were examined using an indirect fluorescent antibody (IFA) method adapted from Holborow and Johnson (1969). The fluorescent conjugate used was FITC-anti-human globulin (MF01, Wellcome Reagents, Beckenham, Kent) and the specimens were examined at a magnification of $\times 100$ or $\times 250$ using a fluorescence microscope (Model MiC-3Qi, Polaron Equipment Ltd, Watford) with a Tiyoda Super wide, toric dark ground condenser. The brightness of staining at each dilution was recorded using a scale of,,,,++++++ \pm- . The titration end point was the highest dilution showing + fluorescence.

\section{ELISA METHOD}

The method followed was modified from the technique described for the immunodiagnosis of viral infections by Voller et al. (1976).

\section{Preparation of antigen}

The organisms were cultured and harvested as described above for the indirect fluorescent antibody method, and then washed three times in PBS, and lyophilised. The pellet of bacteria was disintegrated in a Spex Freezer mill (Spex Industries Inc, Metuchen, NJ, USA) in liquid nitrogen. The resulting powder was suspended in $0.1 \mathrm{M} \mathrm{NaCl}$ and examined for the absence of whole bacteria, using the Gram stain method. If the suspension showed few intact bacteria, it was centrifuged and the insoluble material was discarded. The supernatant was adjusted to give $E_{280 \mathrm{~nm}}^{1 \mathrm{~cm}}$ of $1 \cdot 65$. The optimum dilution of this antigen preparation for coating the walls of the polystyrene plates was determined as described by Voller et al. (1976).

\section{Preparation of enzyme-antiglobulin conjugate}

An anti-human globulin-alkaline phosphatase conjugate was prepared as described by Engvall and Perlmann (1972). The sheep anti-human globulin was obtained from Wellcome Reagents (Beckenham, Kent) as a whole immunoglobulin fraction (40 $\mathrm{mg} / \mathrm{ml}$ ). Calf intestine alkaline phosphatase was type VII (Sigma London Chemical Co Ltd, Kingstonupon-Thames, Surrey, KT2 7BH).

\section{Experimental conditions}

All tests were performed in triplicate and the results were expressed as the mean. The Cooke microtitre plates, M29AR (Dynatech, Billingshurst, Sussex), were coated overnight at $4^{\circ} \mathrm{C}$ with $0.2 \mathrm{ml}$ antigen preparation diluted 1:150 in carbonate buffer $\mathrm{pH}$ 9.6. The plates were then washed with PBS-Tween before the addition of $0.2 \mathrm{ml}$ serum diluted $1: 100$ in PBS-Tween buffer, and incubated for two hours at $37^{\circ} \mathrm{C}$. After further washing the $\mathbf{0 . 2} \mathrm{ml}$ anti-human globulin-enzyme conjugate was added for three hours at $37^{\circ} \mathrm{C}$. The optimal dilution for the batch used (determined by a chess board titration) was $1 / 1200$.

The phosphatase substrate was $0.2 \mathrm{ml} p$-nitrophenyl phosphate, $1 \mathrm{mg} / \mathrm{ml}$ (Sigma 104) in $10 \%$ diethanolamine buffer $\mathrm{pH} 9 \cdot 8$. This was added after further washing of the plates, and the incubation was for 30 minutes at room temperature. The reactions were stopped by the addition of $100 \mu \mathrm{l}$ of $3 \mathrm{M}$ sodium hydroxide and the $\mathrm{E}_{400 \mathrm{~nm}}^{1 \mathrm{~cm}}$ was read in a spectrophotometer (Cecil Instruments Ltd, Cambridge, Model CE 343) with a microflow cell attachment linked to a Superspenser (Hook and Tucker Instruments Ltd, Croydon, Surrey).

\section{Case histories}

CASE 1

A woman aged 64 years underwent a left total hip replacement operation for severe osteoarthritis in September 1975. Her immediate postoperative course was uneventful except for some oozing from a haematoma in the wound. Two months later, however, her progress was disappointing in that she was getting pain in the left hip and was still able to walk only with the aid of a crutch.

In February 1976 it was suspected that the hip might be infected as her ESR was $64 \mathrm{~mm} / 1$ hour (Westergren). In April $1976 x$-rays showed definite evidence of infection, and she was admitted to hospital for treatment with antibiotics and traction. Flucloxacillin and clindamycin were prescribed but 
the latter was stopped after 10 days because of the risk of pseudomembranous enterocolitis with longterm treatment, and erythromycin was substituted. These antibiotics were continued but there was no improvement in her symptoms, her ESR remained raised, and in September 1976, one year after the original operation, the prosthesis was removed. At operation both femoral and acetabular components were found to be loose, but there was no gross evidence of active infection.

\section{CASE 2}

A woman aged 73, with a two-year history of painful left hip due to osteoarthritis, underwent a left total hip replacement operation in April 1974. After this operation she was never free of pain, and two months later her ESR was $71 \mathrm{~mm} / 1$ hour (Westergren). She continued to have pain in the hip and by December $1975 x$-ray changes diagnostic of infection could be seen. In the following month a discharging sinus developed.

She was treated with co-trimoxazole, which was changed after 10 days to flucloxacillin and ampicillin. After one month the ampicillin was discontinued and she was treated with flucloxacillin only from FebI uary 1976 until January 1977. The sinus stopped discharging but she continued to have pain, and in January 1977 the prosthesis dislocated and was removed. At operation the head of the prosthesis was located in a fibrous pseudo cup and the joint contained pus. The acetabular component was loose but the femoral component was firm.

\section{Results}

ORGANISMS ISOLATED FROM PROSTHESES

A pure heavy growth of $P$. magnus was obtained in the anaerobic pour-plate in both cases. The colonies were so numerous that accurate counts could not be made, but it was estimated that more than 50000 organisms were present in the broth after washing the prosthesis in each case. The organism was not found in any of the other cultures from case 1 , but in case 2 the same organism was isolated from all anaerobic cultures and subcultures.

The strain isolated from case 1 was found to be sensitive to penicillin, flucloxacillin, fucidin, tetracycline, chloramphenicol, and metronidazole but resistant to co-trimoxazole, erythromycin, and lincomycin. The strain isolated from case 2 was sensitive to fucidin, tetracycline, chloramphenicol, metronidazole, erythromycin, and lincomycin but resistant to penicillin, flucloxacillin, and co-trimoxazole.

INDIRECT FLUORESCENT ANTIBODY STUDIES Serum samples from 91 blood donors were tested against both of the organisms isolated and were found to be negative at dilutions of 1 in 20 or greater, but nine of these 'normal' sera showed weak fluorescence at a dilution of 1 in 10. These results suggest that detectable levels of antibodies to $P$. magnus are not common in the general population. Serum samples obtained preoperatively from both patients were negative at all dilutions tested but sera taken at intervals after operation (Table) showed strong fluorescence, suggesting that infection by $\boldsymbol{P}$. magnus was acquired at or after the time of operation. It is noteworthy that in case 1 the last serum sample, taken 20 months after the operation for removal of the prosthesis, had a titre of 1 in 80 whereas the serum taken just before this operation was positive up to a dilution of 1 in 1280 . These findings strongly support the view that the antibody response to $P$. magnus was specific and directed against the organisms infecting the hip prosthesis.

\section{ELISA STUDIES}

The same sera from blood donors which were tested in the indirect fluorescent antibody (IFA) test were

Table Results of serological studies on cases 1 and 2

\begin{tabular}{|c|c|c|c|c|c|}
\hline \multicolumn{3}{|c|}{$\begin{array}{l}\text { Case } 1 \\
\text { Prosthesis removed after } 12 \text { months }\end{array}$} & \multicolumn{3}{|c|}{$\begin{array}{l}\text { Case } 2 \\
\text { Prosthesis removed after } 31 \text { months }\end{array}$} \\
\hline $\begin{array}{l}\text { Months after } \\
\text { arthroplasty }\end{array}$ & $\begin{array}{l}\text { IFA test } \\
\text { (reciprocal of titre) }\end{array}$ & $\begin{array}{l}E L I S A \\
\left(E_{400 n m}^{1 c m}\right)\end{array}$ & $\begin{array}{l}\text { Months after } \\
\text { arthroplasty }\end{array}$ & $\begin{array}{l}\text { IFA test } \\
\text { (reciprocal of titre) }\end{array}$ & $\begin{array}{l}E L I S A \\
\left(E_{400 n m}^{1 c m}\right)\end{array}$ \\
\hline $\begin{array}{r}0 \\
2 \\
7 \\
8 \\
9 \\
10 \\
12 \\
16 \\
19 \\
32\end{array}$ & $\begin{array}{r}<10 \\
80 \\
640 \\
640 \\
640 \\
640 \\
1280 \\
1280 \\
\text { ND } \\
80\end{array}$ & $\begin{array}{l}0.002 \\
0.002 \\
0.33 \\
0.35 \\
0.35 \\
0.43 \\
0.41 \\
0.36 \\
0.34 \\
\text { ND }\end{array}$ & $\begin{array}{r}0 \\
9 \\
22 \\
23 \\
25 \\
34 \\
35 \\
37\end{array}$ & $\begin{array}{r}<10 \\
1280 \\
1280 \\
1280 \\
1280 \\
640 \\
1280 \\
1280\end{array}$ & $\begin{array}{l}0.06 \\
0.41 \\
0.42 \\
0.47 \\
0.45 \\
0.38 \\
0.37 \\
0.33\end{array}$ \\
\hline
\end{tabular}

ND $=$ not determined. 
examined in the ELISA method, and found to give a low absorbance value. The $\mathrm{E}_{400 \mathrm{~mm}}^{1 \mathrm{~cm}}$ in 88 of 91 cases was less than $0 \cdot 10$ and less than $0 \cdot 17$ in the remaining three cases. These results confirm that levels of antibody to $P$. magnus in the general population are low. The results of ELISA tests with the patients' sera (Table) reflect the results of the IFA tests.

\section{Discussion}

These findings illustrate the value of careful bacteriological examination of prosthetic joints which are removed for suspected infection. It is particularly important to make suitable cultures as soon as the prosthesis is removed. Quantitation of the number of organisms present on the metal or plastic can then be helpful in differentiating contaminating bacteria, which may be introduced during surgery, from organisms responsible for infection. Recent work has shown that anaerobic organisms can frequently be isolated from such material, and the importance of anaerobic cultures is evident. No special media designed for anaerobic isolation were used in this work but our findings indicate that further development of our methods for the isolation of such organisms would be worthwhile. Since these cases were first noted anaerobic bacteria have been isolated in our laboratory from four further cases of infection in joint prostheses. The organisms concerned were Proprionibacterium acnes, $P$ magnus, $P$. asaccharolyticus, and a further peptococcus not speciated. In each case they were isolated in pure culture.

It is not possible to establish whether these bacteria were the primary cause of the failure of the hip prostheses in the two cases described in this paper or if failure was due to surgical or mechanical problems which also gave rise to an avascular environment, promoting the possibility of infection by anaerobes. However, the demonstration of radiological changes considered to be typical of infection suggest that the presence of the bacteria was responsible for the eventual failure of the arthroplasty procedure.

The peptococci are generally inactive, being nonsaccharolytic and non-proteolytic and in animal inoculation tests not especially invasive or pathogenic. However, our work clearly shows that there is an immunological response in the host implicating the organism as an opportunistic pathogen. These findings demonstrate the value of storing patients' sera obtained before operation and during the extended period of postoperative care. Serial estimations of antibody levels made retrospectively support the validity of the bacteriological findings and can also permit speculation as to the time when the infection was acquired.

In case 1 described in this paper, antibody to $P$. magnus detectable in the IFA test developed during the first two months after arthroplasty. It might therefore be inferred that infection occurred at the time of operation, in which case the organism probably originated from the patient's own skin. It could be suggested, however, that the antibody detected in the IFA test was IgM, which the ELISA test failed to detect, and that the infection was established during the first two months after operation.

In case 2 the lack of serum specimens during the first eight months after operation prevents speculation on the time of infection. It is clear, however, that infection was well established by the ninth month after operation.

The interpretation of serological results on postoperative serum specimens with respect to organisms of doubtful pathogenicity can be made only if a preoperative serum sample has been stored for comparison. The storage of fortnightly serum samples taken soon after the operation in the two cases would have allowed us to make a more accurate estimate of the time at which infection occurred. The development of serological tests for such organisms using methods similar to those described in this paper is feasible and could permit prompt and appropriate therapy to be instituted in some cases, thereby prolonging the useful life of the prosthesis.

We acknowledge the cooperation of the surgeons of the Royal National Orthopaedic Hospital, whose patients have been studied in this investigation. We are grateful to Dr A. T. Willis, of the Public Health Laboratory, Luton for the identification of the peptococcus as $P$. magnus.

The work was supported in part by the Sir William Coxen Trust Fund.

\section{References}

Engvall, E., and Perlmann, P. (1972). Enzyme-linked immunosorbent assay, ELISA. III. Quantitation of specific antibodies by enzyme-labelled anti-immunoglobulin in antigen coated tubes. Journal of Immunology, 109, 129-135.

Evanski, P. M., Waugh, T. R., Prietto, C. A., and Orofino, C. F. (1977). Anaerobic infection after total hip replacement: report of three cases. Clinical Orthopaedics and Related Research, 126, 178-180.

Holborow, E. J., and Johnson, G. D. (1969). The immunofluorescent test for serum antinuclear factor. Broadsheet 65, Association of Clinical Pathologists, London.

Kidby, R. (1974). Immunofluorescent detection and quantitation of autoantibodies-development of a routine service. Medical Laboratory Technology, 31, 305-310. 
Lambe, D. W. Jr., Vroon, D. H., and Rietz, C. W. (1974). Infections due to anaerobic cocci. In Anaerobic Bacteria: Role in Disease, edited by A. Balows, R. M. DeHaan, V. R. Dowell Jr., and L. B. Guze, pp. 585-599. Thomas, Springfield, Illinois, USA.

Nelson, J. P. (1977). Deep infection following total hip arthroplasty. Journal of Bone and Joint Surgery, 59A, 1042-1044.

Voller, A., Bidwell, D., and Bartlett, A. (1976). Microplate enzyme immunoassays for the immunodiagnosis of virus infections. In Manual of Clinical Immunology, edited by N. R. Rose and H. Friedman, chapter 69, pp. 506-512. American Society for Microbiology, Washington DC, USA.

Requests for reprints to: Dr A. G. Taylor, Standards Laboratory for Serological Reagents, Central Public Health Laboratory, Colindale Avenue, London NW95HT, UK. 